\title{
Biodegradable Colour Polymeric Film (Starch-Chitosan) Development: Characterization for Packaging Materials
}

\author{
M. Z. I. Mollah ${ }^{1}$, N. Akter ${ }^{2}$, F. B. Quader ${ }^{2}$, S. Sultana ${ }^{1}$, R. A. Khan ${ }^{1}$ \\ ${ }^{1}$ Nuclear and Radiation Chemistry Division, Institute of Nuclear Science and Technology, Bangladesh Atomic \\ Energy Commission, Dhaka, Bangladesh \\ ${ }^{2}$ Department of Applied Chemistry and Chemical Engineering, University of Dhaka, Dhaka, Bangladesh \\ Email: "zahirul1973@yahoo.com
}

Received 13 December 2015; accepted 8 January 2016; published 12 January 2016

Copyright $(2016$ by authors and Scientific Research Publishing Inc.

This work is licensed under the Creative Commons Attribution International License (CC BY).

http://creativecommons.org/licenses/by/4.0/

(c) (i) Open Access

\begin{abstract}
Biodegradable starch-based chitosan reinforced composite polymeric films were prepared by casting. The chitosan content in the films was varied from $20 \%$ to $80 \%(w / w)$. Tensile strength (TS) was improved significantly with the addition of chitosan but elongation at break (EB \%) of the composites decreased. Tensile strength of the composites raised more with the addition of the acacia catechu content in the films varied from $0.05 \%$ to $0.2 \%(w / w)$. The better thermal stability of this prepared film was confirmed by thermo-gravimetric analysis. Structural characterization was done by Fourier transform infrared spectroscopy. Surface morphologies of the composites were examined by scanning electron microscope (SEM) which suggested sufficient homogenization of starch, chitosan and acacia catechu. Water uptake was found lower for final composites in comparison to starch/chitosan and chitosan films. The satisfactory rate of degradation in the soil is expected that the final composite film is within less than 6 months. The developed films intended to use as the alternative of synthetic non-biodegradable colored packaging films.
\end{abstract}

\section{Keywords}

Chitosan, Starch, Acacia Catechu, Composite, Biodegradable, Packaging

\section{Introduction}

Generally, plastic products are derived from non-renewable fossil fuels and are non-biodegradable [1] [2]. The ${ }^{*}$ Corresponding author.

How to cite this paper: Mollah, M.Z.I., Akter, N., Quader, F.B., Sultana, S. and Khan, R.A. (2016) Biodegradable Colour Polymeric Film (Starch-Chitosan) Development: Characterization for Packaging Materials. Open Journal of Organic Polymer Materials, 6, 11-24. http://dx.doi.org/10.4236/ojopm.2016.61002 
production of plastic materials has been increasing considerably due to the extensive growth of the world population. The improper disposal of the enormous volume of petroleum-derived plastics leads to environmental pollution and raises the question - how to replace them with natural polymers, being biodegradable and renewable resources [3]. Biological recycling of polymers must be considered as an alternative to more traditional recycling procedures and this has stimulated researchers to synthesize new polymers that can be returned to the biological cycle after use. Therefore the use of agricultural biopolymers that are easily biodegradable would solve these problems [4]. Over the last decade, the interest in biodegradable films and films-made packaging materials from renewable and natural polymers has increased. Recently, scientists have devoted much energy to developing novel biodegradable hydrogels material for drug delivery [5], tissue engineering [6], sensors [7], contact lenses [8], purification [9], etc.

For coloring film a natural resin Khair (Acacia catechu) is used. Khair is a moderate size deciduous tree with rough dark gray brown bark. It belongs to family Leguminoseae-mimoseae. The most important product obtained from Acacia catechu var. catechu proper is Khair or catechu. This is obtained by boiling chips of heartwood with water in specially designed earthen pitchers and allowing the concentrate to cool and crystallize. As sold in local market, catechu is found in irregular pieces or small square blocks of grayish black color, which on breaking show a crystalline fracture [10]. Catechin oxygenase, a key enzyme in the degradation of catechin, is present in fungi and bacteria [11]. Color of catechu-water solution is dark brown. This solution is acidic in nature. The chief chemical constituent of catechu is catechin. Catechin is polyphenolic antioxidant plant secondary metabolite. Catechin possesses two benzene rings (called the A- and B-rings) and a dihydropyranheterocycle (the C-ring) with a hydroxyl group on carbon 3. The A ring is similar to a resorcinol moiety while the B ring is similar to a catechol moiety. There are two chiral centers on the molecule on carbons 2 and 3 . It has therefore four diastereoisomers. Two of the isomers are in trans-configuration, called catechin and the other two are in cis-configuration, called epicatechin [12].

Chitin is the second most abundant natural polymeric material. It is a linear polysaccharide composed of 2-ace-tamido-2-deoxy-D-glucosidic bonds. Conversely, chitosan is an amino polysaccharide comprising an unbranched chain of $\beta(1 \rightarrow 4) 2$-amino-2-deoxy-D glucopyranose residue. Chitosan has been extensively studied in pharmaceutical and medical fields for its biodegradability, biocompatibility, bioactivity, and interesting physicochemical properties partially acetylated chitosan having about 50\% D-glucosamine unit which is only able to dissolve in water [12]. This biopolymer is bio-renewable, biodegradable, and bio-functional. The presence of active groups in chitosan molecules favored it to use chitosan in many fields. Chitosan films are now used in making biodegradable packaging material. Several studies have indicated the bacteriostatic [13]-[17] and fungistatic [18] activities of Chitosan. Because of reactive amino and hydroxyl functional groups, chitosan is frequently blended with other polymers [19]. Starch and chitosan are hydrocolloids with well-known good film forming capacities. Both have been reported as potential materials for packaging [20].

Starch, a natural renewable polysaccharide from a great variety of crops, is one of the promising raw materials for the production of biodegradable plastics because of its low cost, availability as a renewable resource, biodegradable and the innocuous degradation products. It has already been widely researched as an important raw material for environmental and biomedical applications. Starch is a carbohydrate consisting of a large number of glucose units joined together by glycosidic bonds. It consists of two types of molecules: the linear and helical amylose and the branched amylopectin [12]. But pure starch based materials are hydrophilic and their mechanical properties decrease with the water intake [21] [22]. To overcome this behavior, starch can be blended with other polymeric material [23] like chitosan. The application of pure starch films is extremely limited due to the high hydrophilicity and deficient mechanical properties of starch [24] [25].

The objective of the present research was developing colored films based on starch and chitosan by using acacia catechu. The mechanical properties of the prepared films were measured. Molecular interactions of components present in films were examined by Fourier Transform Infrared (FT-IR) spectroscopy. Thermal properties of the films were investigated by Differential Scanning Calorimetric (DSC) studies. Surface topography of the films was investigated by Scanning Electron Microscopy (SEM). The water uptake and the degradation test in soil were also performed.

\section{Materials and Methods}

\subsection{Materials}

Chitosan (powder, viscosity: $200 \mathrm{cP}$ ) and starch (potato starch) were purchased from Sigma-Aldrich Chemie 
GmbH, Germany. Acacia catechu bought from the local market of Bangladesh. The chemical formulas of chitosan, starch and acacia catechu, Figure 1.

\subsection{Preparation of Biopolymeric Films by Casting}

Solution of $1 \%$ chitosan (w/w) was made using $2 \%(\mathrm{w} / \mathrm{w})$ acetic acid solution. The chitosan films were prepared by casting onto flat silicon-coated Petri dishes and allowed to dry for $24 \mathrm{~h}$ at room temperature with $35 \%$ relative humidity. Dried films were peeled off manually using spatula and stored in the desiccators prior to characterization. Starch was dissolved in de-ionized hot $\left(70^{\circ} \mathrm{C}\right)$ water with constant stirring. Then starch and chitosan solutions were mixed together at different proportions. Composite films were prepared by solution casting at the same parameters (Figure 2). The water soluble Acacia catechu was mixed with the chitosan + starch solution at different proportions and the films are prepared by casting (Table $1 \&$ Table 2). Thickness of films was maintained to $100 \mu \mathrm{m}$.

\subsection{Mechanical Properties of the Films}

Mechanical properties like TS, Tm (tensile modulus), and $\mathrm{Eb}$ of the films were investigated by the Universal Testing Machine (Hounsfield series S testing machine, UK, H50 KS-0404) with a crosshead speed of $1 \mathrm{mms}^{-1}$ at

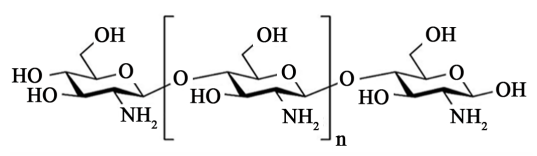

(a)

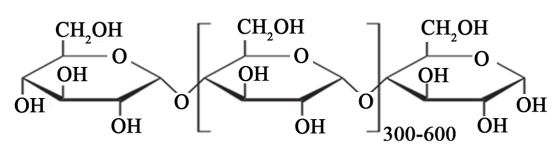

(b)

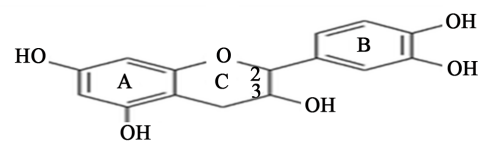

(c)

Figure 1. Structure of (a) chitosan, (b) starch and (c) catechin.

Table 1. Formulations of chitosan/starch film.

\begin{tabular}{ccc}
\hline Formulation & Starch (\%) & Chitosan (\%) \\
\hline 1 & 80 & 20 \\
2 & 70 & 30 \\
3 & 60 & 40 \\
4 & 50 & 50 \\
5 & 20 & 80 \\
\hline
\end{tabular}

Table 2. The formulations of starch + chitosan + acacia catechu film.

\begin{tabular}{ccccc}
\hline \multirow{2}{*}{$\begin{array}{c}\text { Acacia catechu concentration } \\
\text { in film formulation (wt\%) }\end{array}$} & \multicolumn{4}{c}{ Concentration (wt\%) of film components after casting (in dry film) } \\
\cline { 2 - 5 } & Starch & Chitosan & Acacia catechu & Total \\
\hline 0.05 & 47.62 & 47.62 & 4.76 & 100 \\
0.1 & 45.46 & 45.46 & 9.08 & 100 \\
0.15 & 43.48 & 43.48 & 13.04 & 100 \\
\hline
\end{tabular}




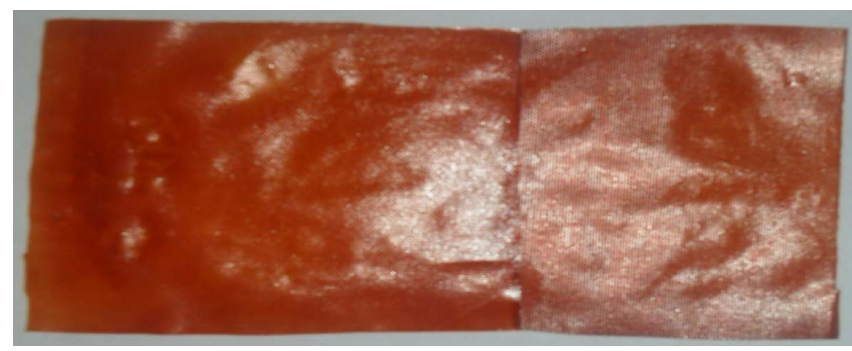

Figure 2. Prepared biodegradable colour film.

a span distance of $25 \mathrm{~mm}$. The dimensions of the test specimen were: $60 \mathrm{~mm} \times 15 \mathrm{~mm} \times 0.01 \mathrm{~mm}$. The experiment was carried out according to the European standard (ISO/DIS 527-1:2010).

\subsection{Thermal Properties Analysis of the Films}

The thermo mechanical (TM) test of the films was taken using computer controlled Differential Scanning Calorimeter (Model: DSC-60 Supplier: Shimadzu Corp.). The temperature range was maintained at $30^{\circ} \mathrm{C}$ to $500^{\circ} \mathrm{C}$ and the temperature was increased at a rate of $10^{\circ} \mathrm{C} / \mathrm{min}$. the flow rate of nitrogen gas was $20 \mathrm{ml} / \mathrm{min}$. Sample weights were $7.82 \mathrm{mg}$.

\subsection{Fourier Transform Infra Red (FTIR) Spectroscopy}

FTIR spectra of the films were recorded using a Spectrum One spectrophotometer (Perkin-Elmer) equipped with an attenuated total reflectance (ATR) device for solids analysis and a high linearity lithium tantalate (HLLT) detector. Spectra were analyzed using the Spectrum 6.3.5 software. Films were stored at room temperature for 72 minutes in a desiccator containing saturated $\mathrm{NaBr}$ solution to ensure a stabilized atmosphere of $59.1 \% \mathrm{RH}$ at $20^{\circ} \mathrm{C}$. Films were then placed onto a zinc selenide crystal, and the analysis was performed within the spectral region of $650-4000 \mathrm{~cm}^{-1}$ with 16 scans recorded at a $4 \mathrm{~cm}^{-1} 10$ resolution. After attenuation of total reflectance and baseline correction, spectra were normalized with a limit ordinate of 1.5 absorbance units. Resulting FTIR spectra were compared in order to evaluate the effects of starch filling in the chitosan-based films, based on the intensity and shift of vibrational bands.

\subsection{Scanning Electron Microscopy Analysis (SEM)}

Film samples $(5 \times 5 \mathrm{~mm})$ were deposited on an aluminum holder and sputtered with gold-platinum (coating thickness, 150 - $180 \AA$ ) in a Hummer IV sputter coater. SEM photographs were taken with a Hitachi S-4700 FEG-SEM scanning electron microscope (Hitachi Canada Ltd., Mississauga, ON, Canada) at a magnification of $40,000 \times$, at room temperature. The working distance was maintained between 15.4 and $16.4 \mathrm{~mm}$, and the acceleration voltage used was $5 \mathrm{kV}$, with the electron beam directed to the surface at a $90^{\circ}$ angle and a secondary electron imaging (SEI) detector.

\subsection{Degradation Test}

Degradation tests of the monomer grafted film were performed under humid soil at ambient condition. Up to three weeks of the tests were carried out. Films ware placed inside $10 \mathrm{~cm}$ depth of humid soil and at set time points, samples were taken out cleaned and kept inside desiccators prior to weighting. The formula employed was:

$$
\text { Weight loss } \%=\left\{\left(W_{b}-W_{a}\right) / W_{b} \times 100\right\}
$$

where, $W_{b}=$ weight before placement in soil;

$W_{a}=$ weight after taken out and cleaned.

\subsection{Statistical Analysis}

For each measurement, five samples in each replicate were tested. Analysis of variance and Duncan's multi- 
ple-range tests were used to perform statistical analysis of all results, using PASW Statistics Base 18 software (SPSS Inc., Chicago, IL, USA). Differences between means were considered to be significant when $p \leq 0.05$.

\section{Results and Discussion}

\subsection{Mechanical Properties of Chitosan Reinforced Starch-Based Composite Films}

Chitosan ( $20 \%-80 \% \mathrm{w} / \mathrm{w})$ was added in starch-based films to investigate the effectiveness of chitosan as reinforcing filler. Tensile strength (TS) values of starch-based films was improved significantly $(p \leq 0.05)$ with the addition of chitosan. Figure 3 shows the effect of chitosan on TS values of starch-based films. For 20\%, 30\%, $40 \%, 50 \%$ and $80 \%$ addition of chitosan, the TS values were observed to be $27,30,38,47$, and $53 \mathrm{MPa}$, respectively. The starch-based films became brittle below $20 \%$ chitosan content. So, in this investigation, the minimum amount of chitosan was maintained to $20 \%$ (by wt). It may be mentioned here that only starch could not form films by solution casting. The TS of chitosan films was found to be $56 \mathrm{MPa}$ (denoted 100\% chitosan in Figure 3). The $50 \%$ chitosan content starch-based films were almost transparent but below 50\% chitosan containing films was opaque in nature.

With the rise of strength and modulus, the Eb values of the starch-based films decreased monotonously due to chitosan addition (Figure 4). The Eb values of $20 \%, 30 \%, 40 \%$, 50\%, and $80 \%$ chitosan content films were

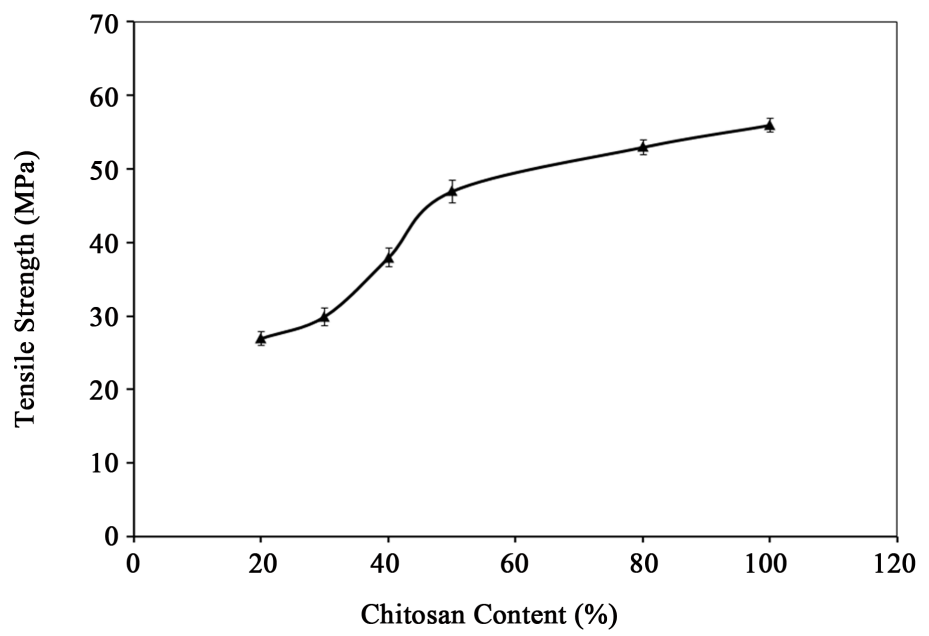

Figure 3. Effect of chitosan on tensile strength of starch-based film.

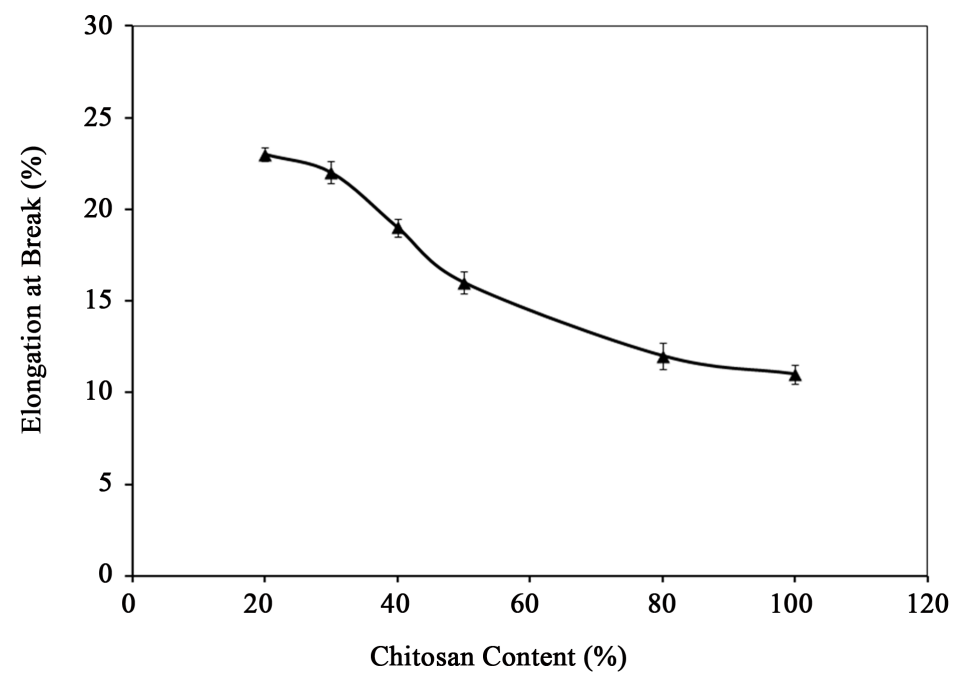

Figure 4. Effect of chitosan on elongation at break of starch-based film. 
$23 \%, 22 \%, 19 \%, 16 \%$, and $12 \%$, respectively. Chitosan acted as a reinforcing agent in starch-based biodegradable films. Thus, higher content of chitosan can render the films stiffer. As a result, decrease in Eb values was observed. Similar results were reported by Pinotti et al. [26] who indicated the reduction in methylcellulose (MC) film flexibility with increasing chitosan concentration. Khan et al. [27] reported that chitosan incorporation (5\% - 36\% by wt) in methylcellulose-based films significantly improved the strength of the films with the reduction of viscoelasticity. The 50\% chitosan containing starch-based films was considered as the optimum because the films had good strength (47 MPa) and modulus (550 MPa) and optimum Eb (16\%) values. Moreover, the appearance of the films was quite transparent.

\subsection{Effect of Acacia Catechu on Mechanical Properties of Starch/Chitosan Film}

Tensile strength (TS) values of chitosan/starch-based films were improved significantly with the addition of acacia catechu. Because Acacia Catechu is natural colored resin, like other natural resin it enhances mechanical properties of the film. Figure 5 shows the effect of Acacia Catechu on TS values of starch-based films. For $0.05 \%, 0.1 \%, 0.15 \%, 0.2 \%$ of addition of acacia catechu, the TS values were observed to be $35,45,60,62 \mathrm{MPa}$ respectively. The acacia catechu + starch + chitosan based films became brittle over $0.2 \%$ acacia catechu content. So, in this investigation, the maximum amount of acacia catechu was maintained to $0.2 \%(\mathrm{w} / \mathrm{w})$.

Figure 6 shows with the rise of strength, the elongation at break values of the acacia catechu + starch + chitosan based films decreased monotonously due to the acacia catechu addition. The Eb values of $0.05,0.10,0.15$, 0.2 (wt\%) of addition of acacia catechu the composite films were 22, 19, 13, and 12 respectively. Acacia catechu acted as a reinforcing agent in chitosan/starch-based biodegradable films.

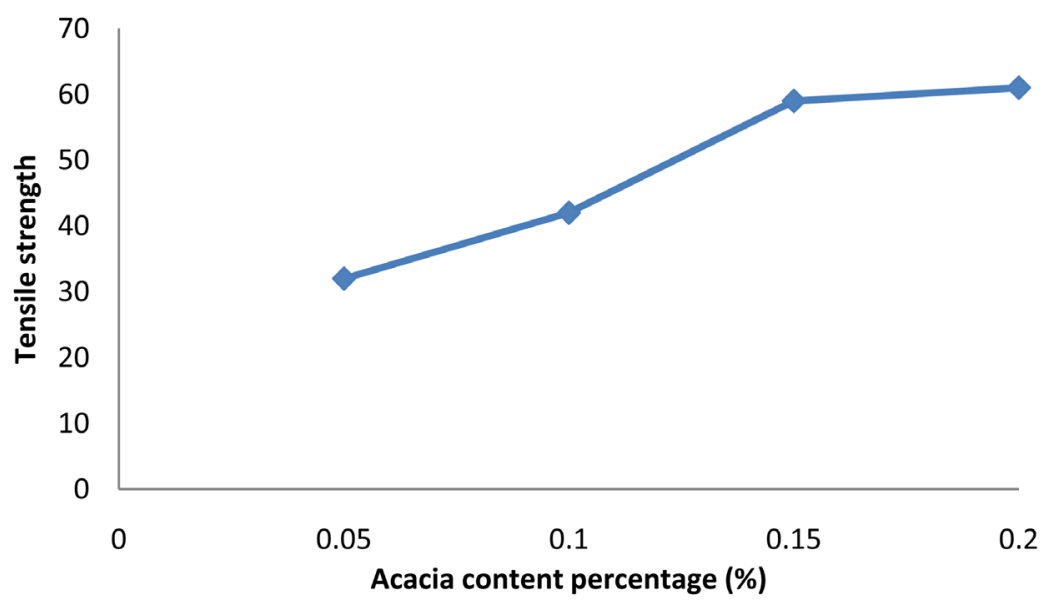

Figure 5. Effect of acacia catechu on tensile strength of starch-chitosan based films.

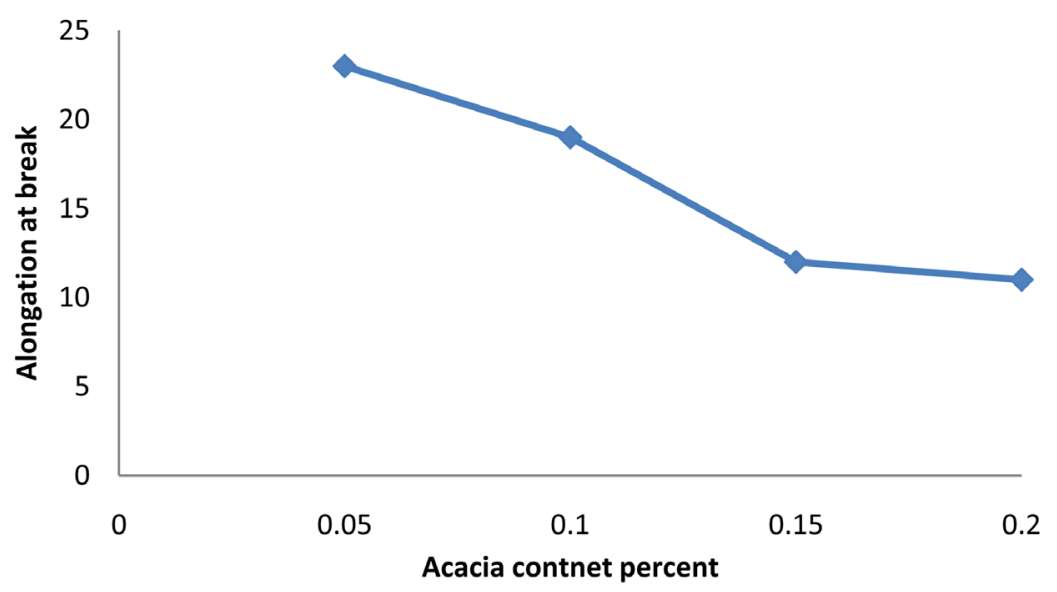

Figure 6. Effect of acacia catechu on elongation at break of starch-chitisan blend films. 


\subsection{Thermal Property of Starch + Chitosan + Acacia Catechu Film}

The thermo gravimetric analysis (TGA) for starch + chitosan + acacia catechu showed in Figure 7. In this experiment, weight of the film (starch + chitosan + acacia catechu) was taken $7.82 \mathrm{mg}$. the TGA data for starch + chitosan + acacia catechu showed two steps in weight loss: one at $100^{\circ} \mathrm{C}$ and another at $390^{\circ} \mathrm{C}-400^{\circ} \mathrm{C}$. Total weight loss at $107.85^{\circ} \mathrm{C}, 226.85^{\circ} \mathrm{C}, 294.66^{\circ} \mathrm{C}, 397.70^{\circ} \mathrm{C}, 561.91^{\circ} \mathrm{C}$ is $4.802 \%, 13.755 \%, 16.169 \%, 11.686 \%$ and $15.17 \%$ respectively. At temperature between $120^{\circ} \mathrm{C}-130^{\circ} \mathrm{C}$ high density poly ethylene degrades completely but this film (starch + chitosan + acacia catechu) at $359.70^{\circ} \mathrm{C}$ degrades only $16.169 \%$. So this biodegradable colored film in comparison with HDPE showed better thermal stability.

\subsection{Fourier Transform Infrared Spectroscopic Analysis}

The absorption peaks of the pure chitosan film (Figure 8) were mainly assignable to the stretching of intra and intermolecular $\mathrm{O}-\mathrm{H}$ and $-\mathrm{CH}_{2} \mathrm{OH}$ vibrations at $3007 \mathrm{~cm}^{-1}$ overlapped with stretching $-\mathrm{NH}_{2}\left(2922 \mathrm{~cm}^{-1}\right)$ and $-\mathrm{NH}$ secondary amides vibrations $\left(2852 \mathrm{~cm}^{-1}\right)$. In addition, $2312 \mathrm{~cm}^{-1}$ corresponds to symmetric and asymmetric C-H vibrations. Amide I vibrational mode at $1745 \mathrm{~cm}^{-1}$ and Amide II at $1458 \mathrm{~cm}^{-1}$ were also clearly observed. The stretching C-N vibration appeared at $1238 \mathrm{~cm}^{-1}$ and stretching C-O band came at $1159 \mathrm{~cm}^{-1}$. Other peaks (from 1097, 1028 and $721 \mathrm{~cm}^{-1)}$ appeared from water molecules present in chitosan.

The FT-IR spectrum of pure starch film is represented in Figure 9. The peak at $1157 \mathrm{~cm}^{-1}$ was found due to the C-O stretching of the C-OH group in starch. The characteristic peak at $1099 \mathrm{~cm}^{-1}$ and $1020 \mathrm{~cm}^{-1}$ were attributed to C-O stretching of the C-O-C group in the anhydroglucose ring. The peak frequencies at 3612, 3730 and $3857 \mathrm{~cm}^{-1}$ were attributed to $\mathrm{O}-\mathrm{H}$ group stretching.

The chitosan/starch-based film was investigated to find out the molecular interactions between chitosan and starch. The spectrum is represented in Figure 10 of starch-chitosan blend film. Both Amide I and Amide II peaks were not shifted. Both the peaks appeared at $1745 \mathrm{~cm}^{-1}$ and $1458 \mathrm{~cm}^{-1}$. The stretching C-N vibration appeared at $1236 \mathrm{~cm}^{-1}$ that was slightly lower than pure chitosan $\left(1238 \mathrm{~cm}^{-1}\right)$. On the other hand, the stretching $\mathrm{C}-\mathrm{O}$ band came at $1161 \mathrm{~cm}^{-1}$ that was slightly higher than pure chitosan $\left(1159 \mathrm{~cm}^{-1}\right)$. The main characteristic

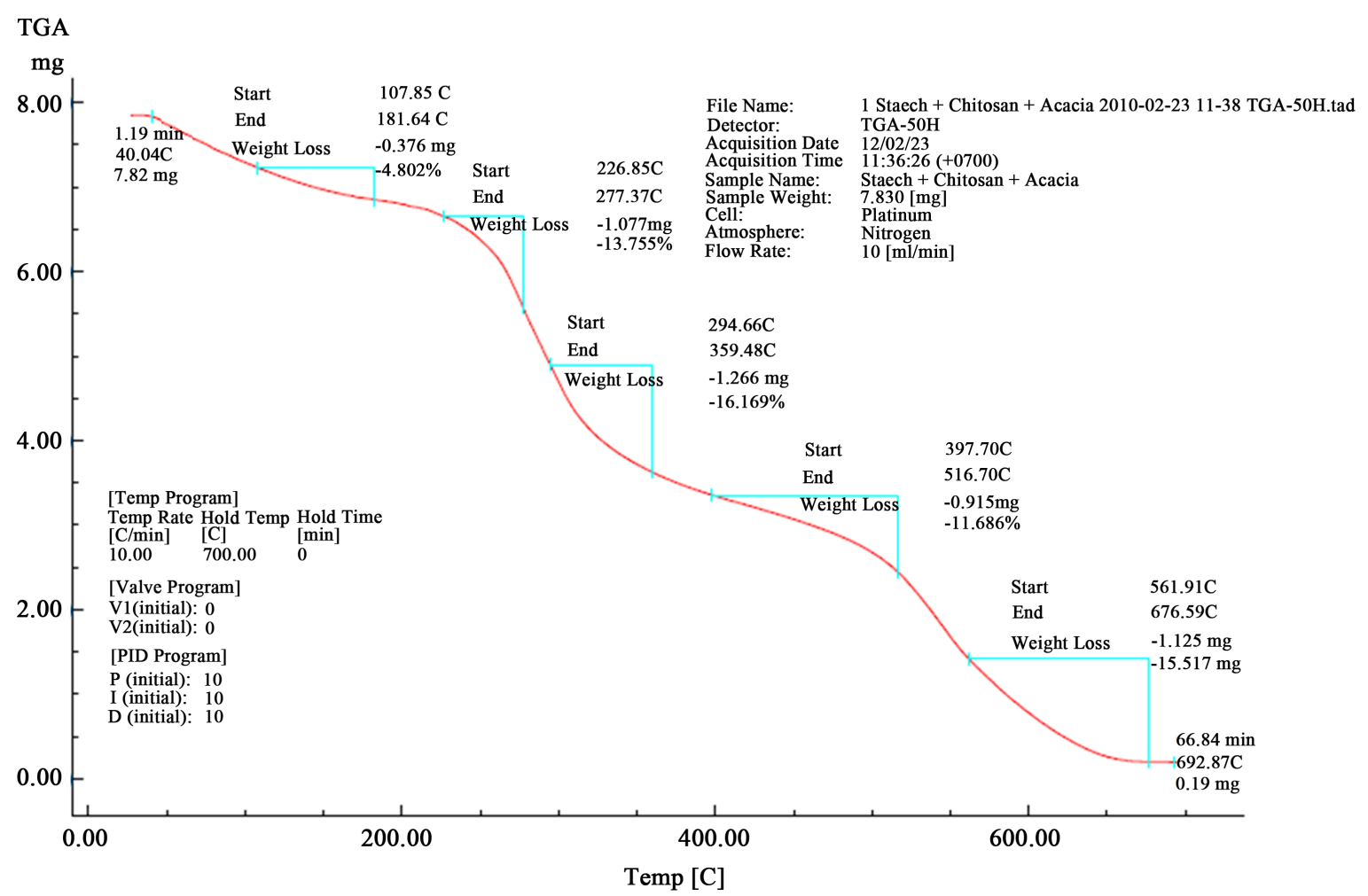

Figure 7. Thermo-gravimetric analysis of starch + chitosan + acacia catechu film. 


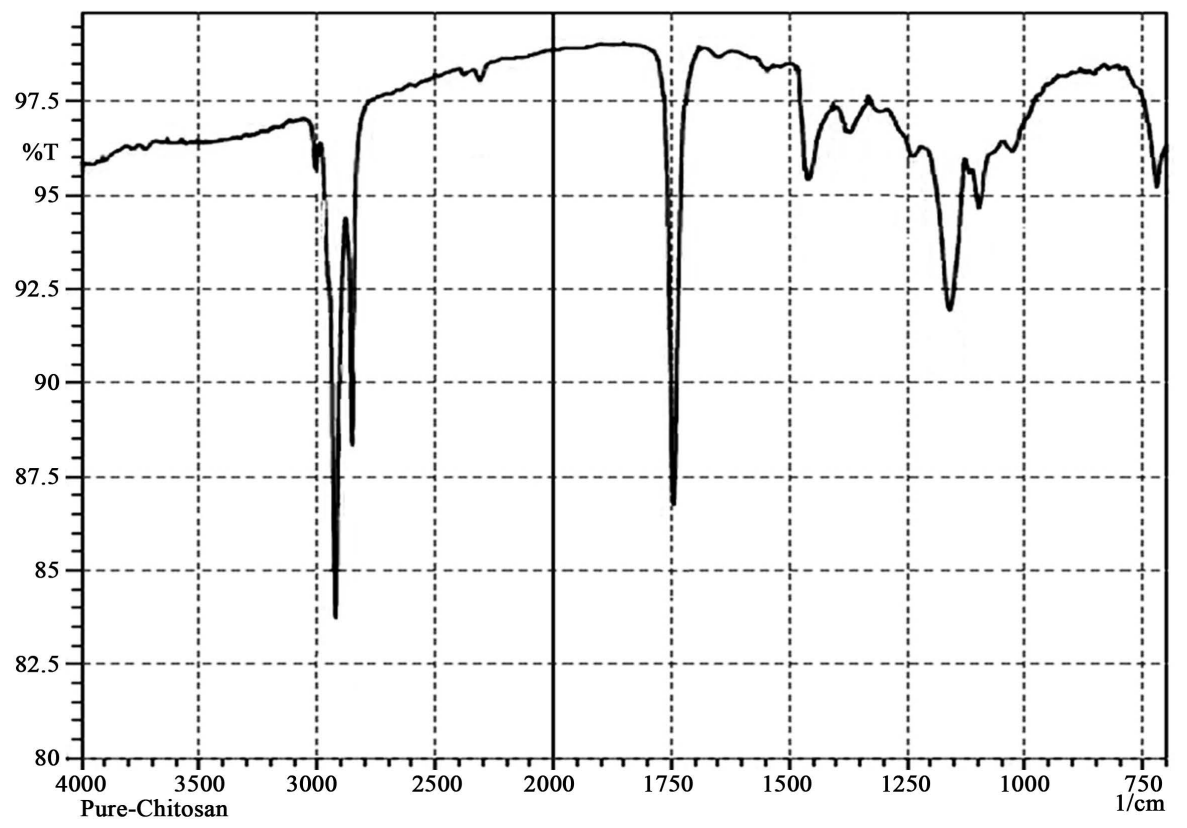

Figure 8. FT-IR spectrum of pure chitosan film.

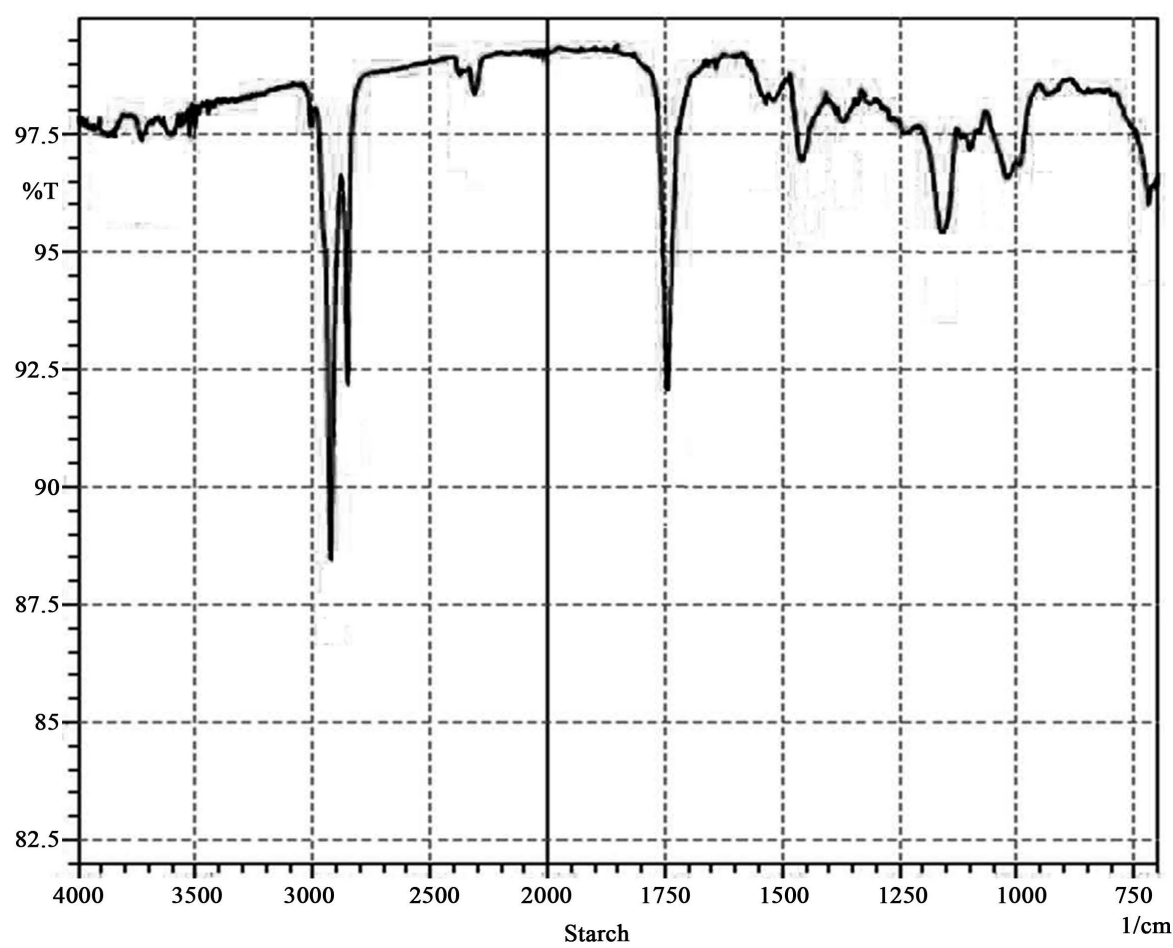

Figure 9. FT-IR spectrum of pure starch.

peak $\left(1099 \mathrm{~cm}^{-1}\right)$ of starch (C-O stretching from C-O-C group) was not shifted. From this spectrum, this is clearly revealed that chitosan was not chemically reacted with starch, as expected. Here, a bio-blend was formed between chitosan and starch.

The chitosan + starch + acacia catechu-based film was investigated to find out the molecular interactions between chitosan, starch and acacia catechu. The spectrum is represented in Figure 11 of starch + chitosan + acacia catechu blend film. Both Amide peaks $\left(1745 \mathrm{~cm}^{-1}\right.$ and $\left.1458 \mathrm{~cm}^{-1}\right)$ are slightly shifted to $1737 \mathrm{~cm}^{-1}$ and 1548 


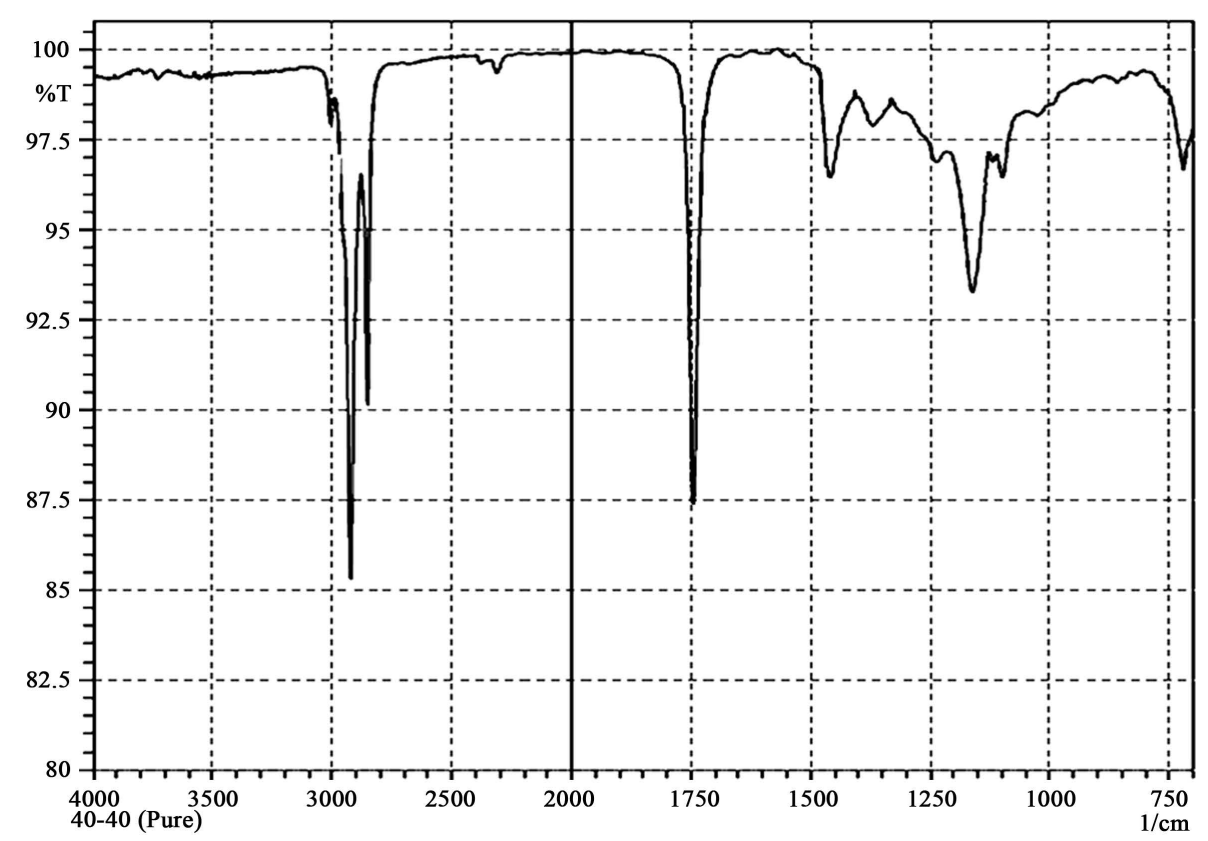

Figure 10. FT-IR spectrum of starch/chitosan film.

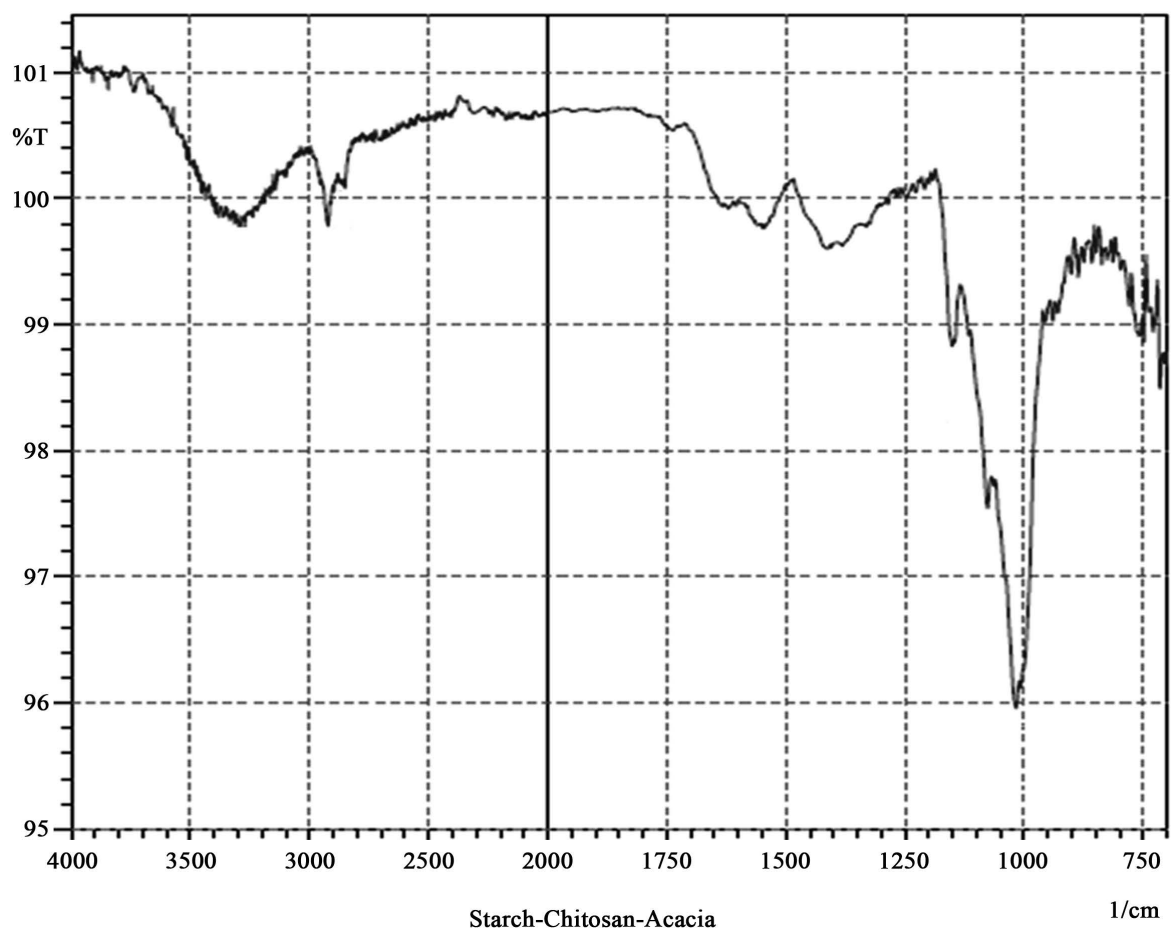

Figure 11. FT-IR spectrum of acacia catechu/starch/chitosan film.

$\mathrm{cm}^{-1}$ Acacia catechu might be reacted with amide group of chitosan or may be hydrogen bond formed. The absorption peaks $\left(3302 \mathrm{~cm}^{-1}\right.$ and $2872 \mathrm{~cm}^{-1}$ ) of the starch + chitosan + acacia catechu film found broader than the absorption peaks of the pure chitosan film assignable to the stretching of intra and intermolecular $\mathrm{O}-\mathrm{H}$ and $-\mathrm{CH}_{2} \mathrm{OH}$ vibrations at $3007 \mathrm{~cm}^{-1}$ overlapped with stretching $-\mathrm{NH}_{2}\left(2922 \mathrm{~cm}^{-1}\right)$ and $-\mathrm{NH}$ secondary amides vibrations $\left(2852 \mathrm{~cm}^{-1}\right)$ because of $\mathrm{O}-\mathrm{H}$ bond in acacia catechu. A major peak appeared in $1016 \mathrm{~cm}^{-1}$ which indicates $\mathrm{C}-\mathrm{O}$ bond in acacia catechu. 


\subsection{Morphological Study by Using Scanning Electron Microscope (SEM)}

Figure 12 represents the surface morphology of chitosan (a), and chitosan reinforced starch-based films (b). The surface of chitosan films appeared a homogenous, smoother and denser film surface with no gross defects. The smooth and homogenous surface of the films is an indicator of the structural integrity of the observed films, and thus good mechanical properties were obtained. It also indicated better solubilization and homogenization of chitosan in aqueous medium. But chitosan reinforced starch-based films showed rough and irregular surface with bubbles as compared to pure chitosan films.

\subsection{Surface Morphology of the Final Starch + Chitosan + Acacia Catechu Films}

The surfaces of the Acacia Catechu (0.15\% by wt) containing chitosan/starch (50:50)-based films were investigated by scanning electron microscopy (SEM) from low to high magnification. The images are presented in Figures 13(a)-(i). In open eye, the surface of the films was very clear, homogeneous, and shiny. But at $\times 30$ magnifications (a), phase separation is clearly shown which indicated that chitosan/starch (biopolymers) and acacia catechu (natural resin) did not react with each other, as expected. Natural resin was added to improve the mechanical strength and to make the film bioactive to protect the packaged food against bacteria. At medium magnification $(\times 50$, and $\times 100)$, represented by (b) and (c), phase separation is more clearly visible.

With the rise of magnification from $\times 250$ to $\times 1000$; Figures $13(d)$-(f), few defects are found and surfaces look heterogeneous. Dramatic image is observed at $\times 3500$ magnification (f). Here surface is cleaner and appearance is much better than other low magnification images.

At very high magnifications from $\times 7500$ to $\times 40,000$; Figures 13 (g)-(i), surfaces of the films look much better. At $\times 40,000$ magnifications (i) the SEM image of the film is fantastic and indicated more homogeneity. Films are clear from bubbles and irregularities. From this image, it is concluded that a homogeneous film surface appeared using three natural materials. Two biopolymers (chitosan and starch) and one natural resin (acacia catechu) mixed homogeneously and made a fantastic bio-blend for the preparation of biodegradable film for food packaging application.

\subsection{Water Uptake}

The water uptake behavior of chitosan film and chitosan ( $50 \%$ by wt) reinforced starch-based composite films are shown in Figure 14. It was found that water uptake of starch/chitosan composite films were much lower compared to native chitosan films. Both type of films absorbed water very rapidly. After 2 min, chitosan film absorbed $160 \%$ water, whereas the starch/chitosan film absorbed $96 \%$ water. At $10 \mathrm{~min}$, chitosan reached to $176 \%$ and starch/chitosan arrived at $125 \%$ of water uptake then both the films showed a gradual decrease of water uptake and indicated the loss of its mass. After $30 \mathrm{~min}$, the water uptake of chitosan and starch/chitosan films

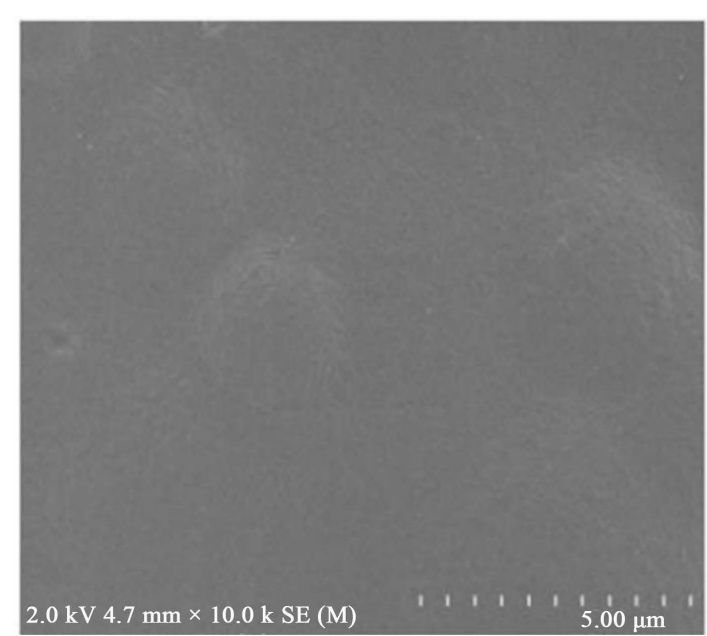

(a)

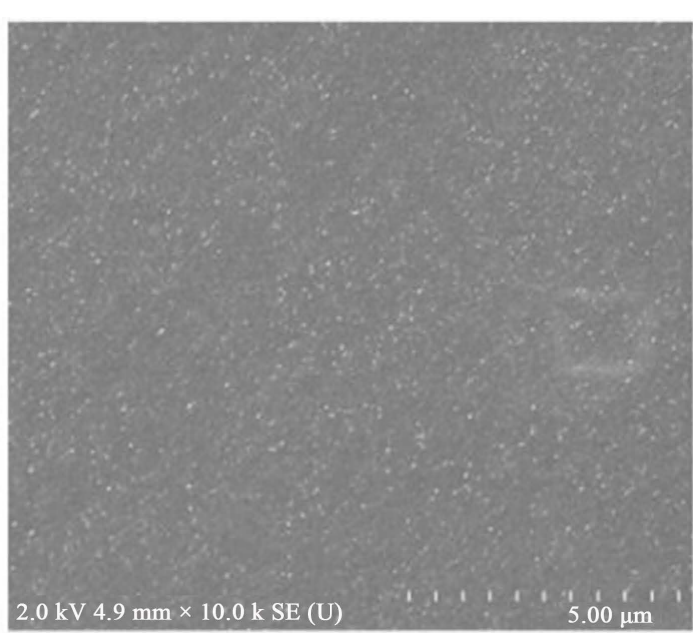

(b)

Figure 12. Surface morphology of (a) chitosan film; and (b) chitosan reinforced (50\% by wt) starch-based film. 


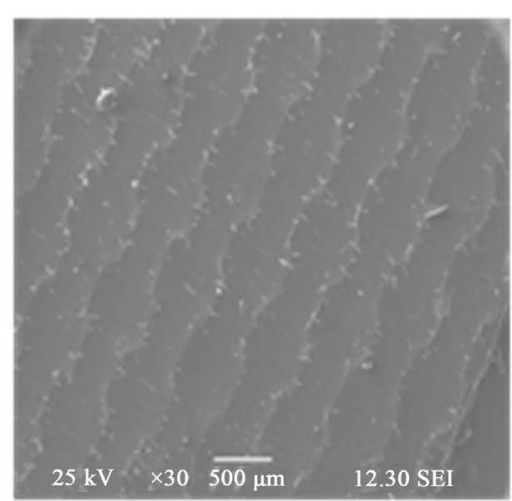

(a)

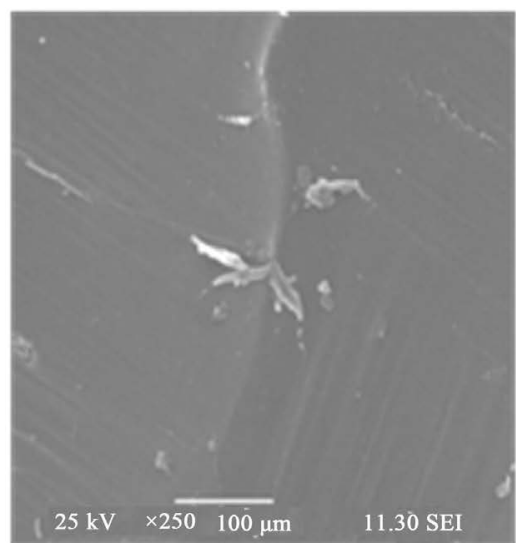

(d)

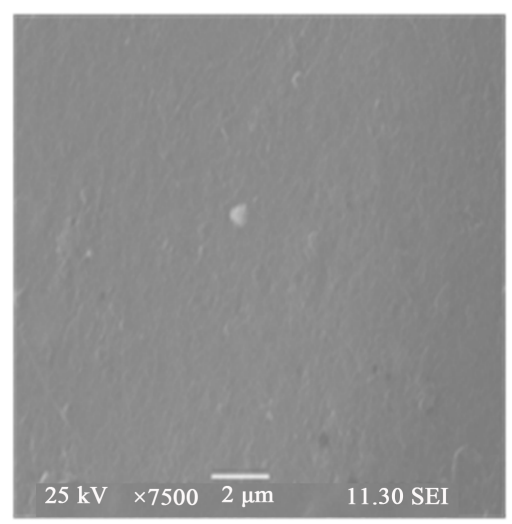

(g)

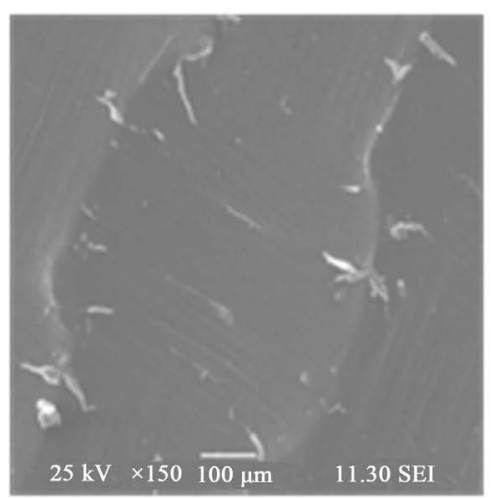

(b)

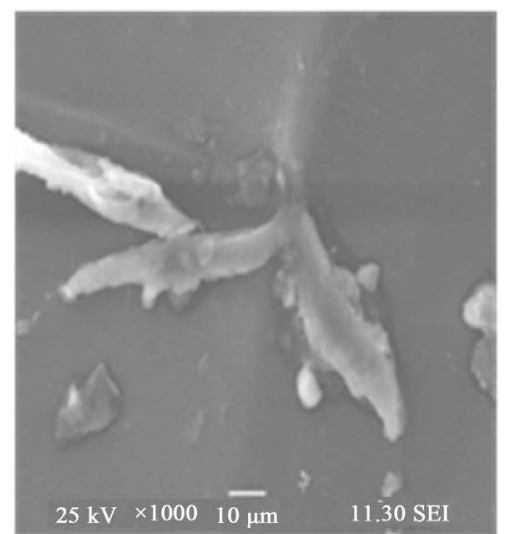

(e)

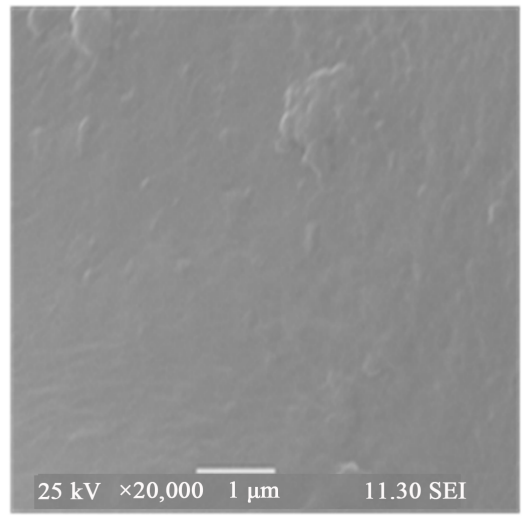

(h)

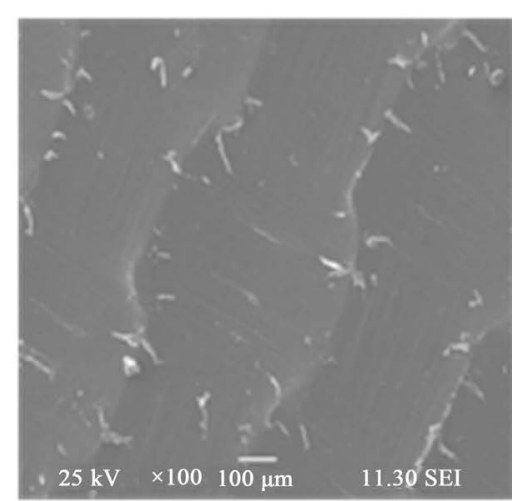

(c)

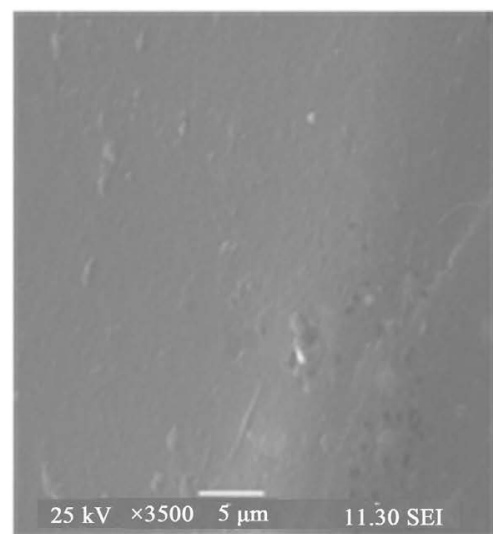

(f)

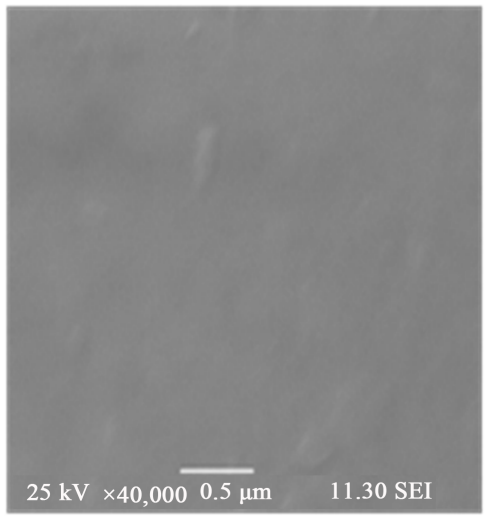

(i)

Figure 13. Surface morphology of starch + chitosan + acacia catechu film.

showed $155 \%$ and $101 \%$ of water uptake. Chitosan is water soluble as the salts of various acids present in D-glucosamino unit. Partially acetylated chitosan has about 50\% D-glucosamine unit that dissolves in water. The starch/chitosan film had better stability in water compared to native chitosan films. The reason could be due to the network formation between starches with chitosan, which prevented water molecules into the films. But both films showed strong affinity of water uptake that indicated strong hydrophilic nature. Both starch and chitosan had plenty of free hydroxyl groups and as a result within few min a significant quantity of water penetrated into the films. But the advantage is the reduction of water uptake due to the reinforcement of chitosan in starch-based films. For example, after $10 \mathrm{~min}$ of immersion in water the starch/chitosan film reduced to $34.83 \%$ of water uptake compared to native chitosan. So, chitosan improved the stability of the starch-based composite 
films in aqueous medium.

But films with acacia catechu were almost static. After $30 \mathrm{~min}$, the water uptake of acacia catechu (0.15 wt\%) + starch + chitosan based film, native chitosan and starch/chitosan films reached to $81 \%, 155 \%$, and $101 \%$.

Acacia catechu $(0.15 \mathrm{wt} \%)+$ starch + chitosan based film had better stability in water compared to chitosan or chitosan/starch-based films. Acacia catechu might be create a network with the biopolymers (chitosan and starch) and formed network, which prevented water molecules penetration into the films.

\subsection{Soil Degradation Test}

In Figure 15, weight loss (\%) was plotted against the degradation time is soil (week). It was observe that the weight loss (\%) is increased with the increasing time. After one week, weight loss is $0.2 \%$, after two weeks,

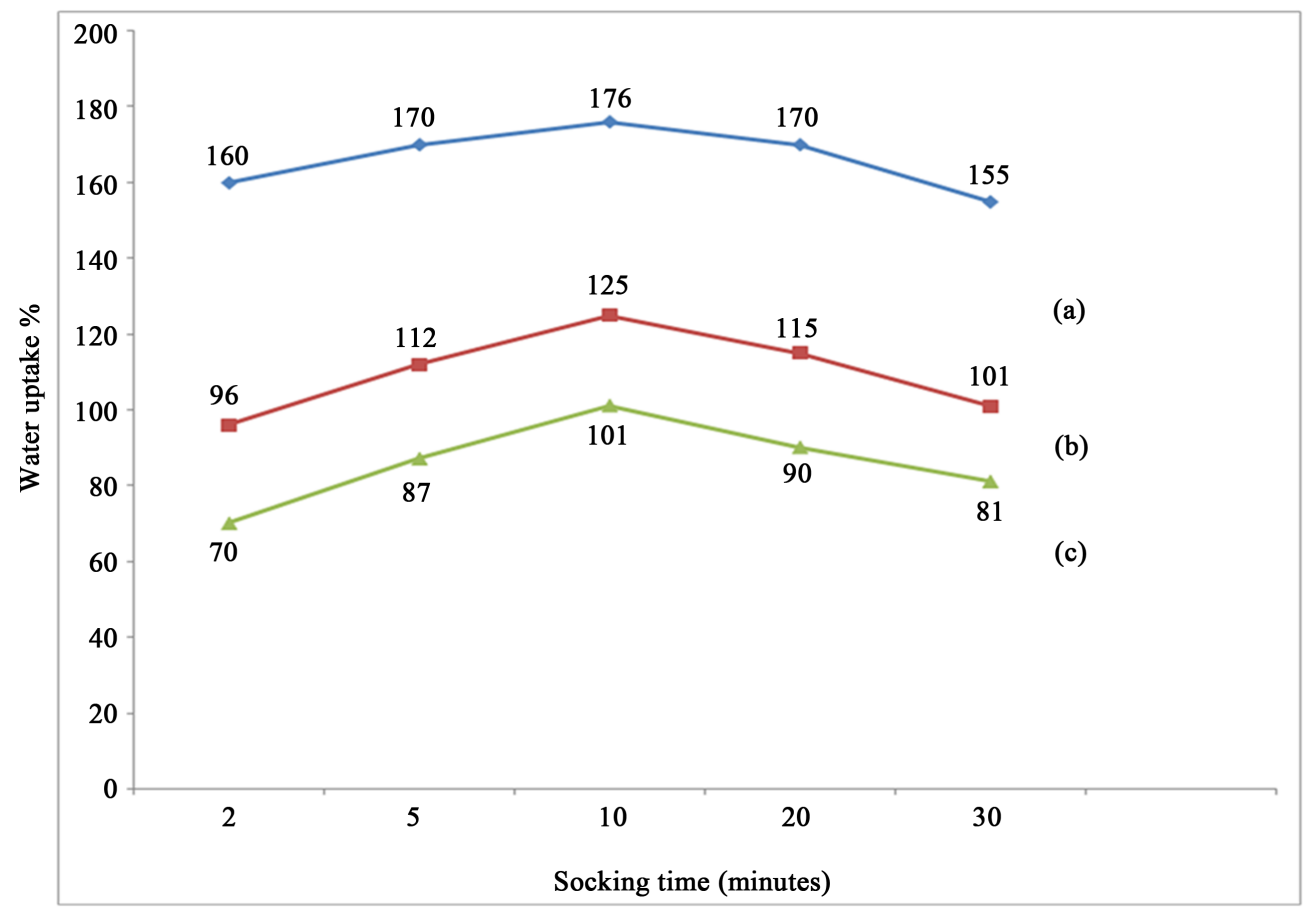

Figure 14. Water uptake of pure chitosan film (a), chitosan/starch film (b) and acacia catechu (0.15\%) + starch + chitosan (c) film.

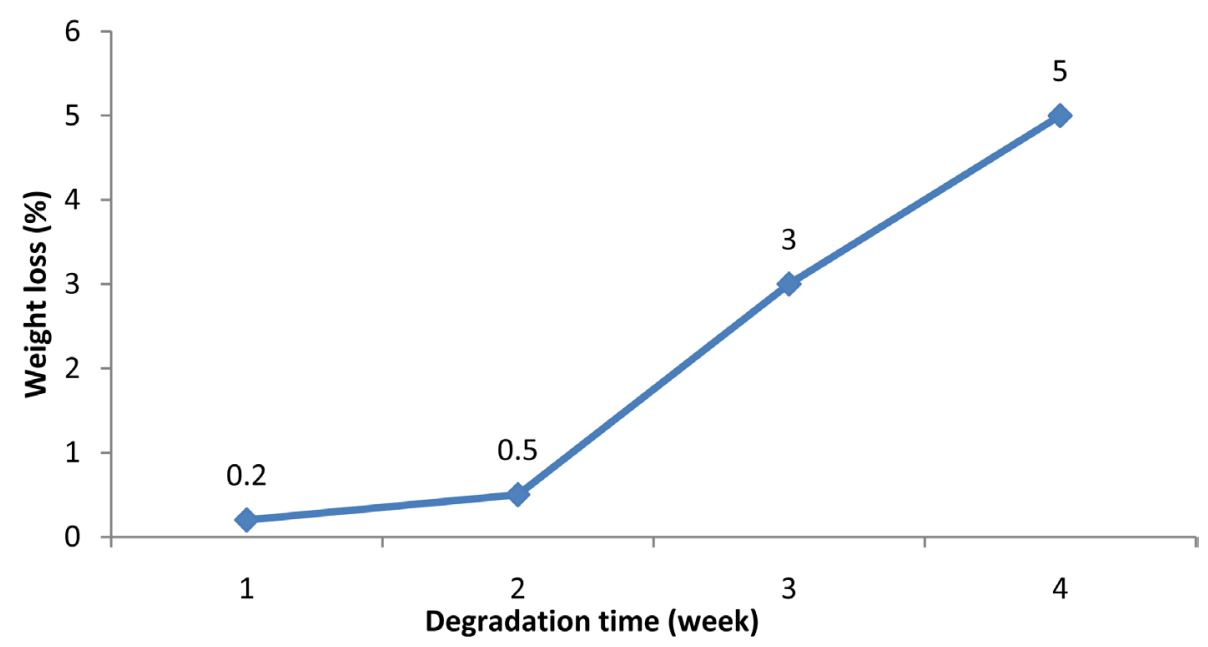

Figure 15. Soil degradation of chitosan/starch based film with acacia catechu (0.15 wt\%). 
weight loss is $0.5 \%$, after three weeks, weight loss is $3 \%$, after four weeks, weight loss is $5 \%$. From this investigation, it was expected that this film will be biodegradable in soil in less than 6 months. Moreover, in the prepared films, Acacia catechu, starch and chitosan, all are natural fiber and totally biodegradable. So, the film did not lose its total inherent biodegradable character after mixing but withstand its stability for longer period.

\section{Conclusion}

Biodegradable film made of starch, chitosan and acacia catechu was successfully developed by solution casting. The key factor of the blend polymer is H-bonding with two polymers. Acacia catechu contributed to the improvement of tensile strength in starch/chitosan films. This film showed good thermal stability also. Structural characterization was done by FT-IR. The surface morphologies indicated better homogenization of the three biopolymers (starch, chitosan and acacia catechu). Water update was lower for acacia catechu incorporated film than starch/chitosan film. Finally, degradation rate in soil is satisfactory also. The prepared films can be used as the colored bio-degradable packaging films.

\section{References}

[1] Pagella, C., Spigno, G. and De Faveri, D.M. (2002) Characterization of Starch Based Edible Coatings. Food and Bioproducts Processing, 80, 193-198. http://dx.doi.org/10.1205/096030802760309214

[2] Ban, W.P., Song, J.G., Argyropoulos, D.S. and Lucia, L.A. (2006) Influence of Natural Biomaterials on the Elastic Properties of Starch-Derived Films: An Optimization Study. Industrial \& Engineering Chemistry Research, 45, 627633. http://pubs.acs.org/doi/abs/10.1021/ie050219s

[3] Daia, H., Changb, P.R., Yua, J. and Maa, X. (2008) N,N-Bis(2-hydroxyethyl)formamide as a New Plasticizer for Thermoplastic Starch. Starch/Stärke, 60, 676-684. http://dx.doi.org/10.1002/star.200800017

[4] Parra, D.F., Tadini, C.C., Ponce, P. and Lugão, A.B. (2004) Mechanical Properties and Water Vapor Transmission in Some Blends of Cassava Starch Edible Films. Carbohydrate Polymers, 58, 475-481. http://dx.doi.org/10.1016/j.carbpol.2004.08.021

[5] Wu, D., Wang, T., Lu, B., Xu, X., Cheng, S. and Jiang, X. (2008) Fabrication of Supramolecular Hydrogels for Drug Delivery and Stem Cell Encapsulation. Langmuir, 24, 10306-10312. http://dx.doi.org/10.1021/la8006876

[6] Khan, F., Tare, R., Richard, O., Oreffo, R. and Bradley, M. (2009) Versatile Biocompatible Polymer Hydrogels: Scaffolds for Cell Growth. Angewandte Chemie International Edition in English, 48, 978-982. http://dx.doi.org/10.1002/anie.200804096

[7] Sorber, J., Steiner, G., Schulz, V., Guenther, M., Gerlach, G. and Salzer, R. (2008) Hydrogel-Based Piezoresistive pH Sensors: Investigations Using FT-IR Attenuated Total Reflection Spectroscopic Imaging. Analytical Chemistry, 80, 2957-2962. http://dx.doi.org/10.1021/ac702598n

[8] Katsoulos, C., Karageorgiadis, L., Vasileiou, N., Mousafeiropoulos, T. and Asimellis, G. (2009) Customized Hydrogel Contact Lenses for Keratoconus Incorporating Correction for Vertical Coma Aberration. Ophthalmic and Physiological Optics, 29, 321-329. http://dx.doi.org/10.1111/j.1475-1313.2009.00645.X

[9] Ha, E.J., Kim, Y.J., An, S.S.A., Kim, Y.K., Lee, J.O. and Lee, S.G. (2008) Purification of His-Tagged Protein Using $\mathrm{Ni}^{2+}$-Poly(2-acetamidoacrylic Acid) Hydrogel. Journal of Chromatography B, 876, 8-12. http://dx.doi.org/10.1016/j.jchromb.2008.10.020

[10] Indian Council of Forestry Research and Education (2010) Dehradun. Khair (Acacia catechu). Dehradun, Forest Research Institute. http://www.frienvis.nic.in/WriteReadData/UserFiles/file/pdfs/Khair.pdf

[11] Arunachalam, M., Mohan Raj, M., Mohan, N. and Mahadevan, A. (2003) Biodegradation of Catechin. Proceedings of the Indian National Science Academy, 69, 353-370.

http://www.new1.dli.ernet.in/data1/upload/insa/INSA_1/20008a2f_353.pdf

[12] The Wikipedia. http://en.wikipedia.org/wiki.

[13] Chen, M.C., Yeh, G.H.C. and Chiang, B.H. (1996) Antimicrobial and Physicochemical Properties of Methylcellulose and Chitosan Films Containing a Preservative. Journal of Food Processing Preservation, 20, 379-390. http://dx.doi.org/10.1111/j.1745-4549.1996.tb00754.x

[14] Helander, I.M., Nurmiaho-Lasilla, E.L., Ahvenainen, R., RhoadeS, J. and Roller, S. (2001) Chitosan Disrupts the Barrier Properties of the Outer Membrane of Gram-Negative Bacteria. International Journal of Food Microbiology, 71, 235-244. http://dx.doi.org/10.1016/S0168-1605(01)00609-2

[15] Knowles, S. and Roller, S. (2001) Efficacy of Chitosan, Carvacrol, and a Hydrogen Peroxide-Based Biocide against Foodborne Microorganisms in Suspension and Adhered to Stainless Steel. Journal of Food Protection, 64, 1542-1548. 
http://www.ncbi.nlm.nih.gov/pubmed/11601703

[16] Coma, V., MartiaL-Gros, A., Garreau, S., Copinet, A., Salin, F. and Deschamps, A. (2002) Edible Antimicrobial Films Based on Chitosan Matrix. Journal of Food Science, 67, 1162-1169. http://onlinelibrary.wiley.com/doi/10.1111/j.1365-2621.2002.tb09470.x/pdf

[17] Möller, H., Grelier, S., Pardon, P. and Coma, V. (2004) Antimicrobial and Physicochemical Properties of ChitosanHPMC-Based Films. Journal of Agricultural and Food Chemistry, 52, 6585-6591. http://dx.doi.org/10.1021/jf0306690

[18] Roller, S. and Covill, N. (1999) The Antifungal Properties of Chitosan in Laboratory Media and Apple Juice. International Journal of Food Microbiology, 47, 67-77. http://dx.doi.org/10.1016/s0168-1605(99)00006-9

[19] Xu, Y.X., Kim, K.M., Hanna, M.A. and Nag, D. (2005) Chitosan-Starch Composite Film: Preparation and Characterization. Industrial Crops and Products, 21, 185-192. http://dx.doi.org/10.1016/j.indcrop.2004.03.002

[20] Garcia, N.L., Ribba, L., Dufresne, A., Aranguren, M.I. and Goyanes, S. (2009) Physico-Mechanical Properties of Biodegradable Starch Nanocomposites. Macromolecular Materials and Engineering, 294, 169-177. http://dx.doi.org/10.1002/mame.200800271

[21] Shorgen, R.L. (1998) Starch: Properties and Materials Applications. In: Kaplan, D.L., Ed., Biopolymers from Renewable Resources, Springer-Verlag, Berlin, 30-46. http://link.springer.com/chapter/10.1007\%2F978-3-662-03680-8_2

[22] Mathew, A.P. and Dufresne, A. (2002) Plasticized Waxy Maize Starch: Effect of Polyols and Relative Humidity on Material Properties. Biomacromolecules, 3, 1101-1108. http://dx.doi.org/10.1021/bm020065p

[23] Wang, X.L., Yang, K.K. and Wang, Y.Z. (2003) Properties of Starch Blends with Biodegradable Polymers. Journal of Macromolecular Science: Part C, 43, 385-409. http://dx.doi.org/10.1081/MC-120023911

[24] Xu, Y.X., Miladinov, V. and Hanna, M.A. (2004) Synthesis and Characterization of Starch Acetates with High Substitution. Cereal Chemistry, 81, 735-740. http://dx.doi.org/10.1094/CCHEM.2004.81.6.735

[25] Thuwall, M., Boldizar, A. and Rigdahl, M. (2006) Extrusion Processing of High Amylose Potato Starch Materials. Carbohydrate Polymers, 65, 441-446. http://dx.doi.org/10.1016/j.carbpol.2006.01.033

[26] Pinotti, A., Garcia, M.A., Martinoa, M.N. and Zaritzkya, N.E. (2007) Study on Microstructure and Physical Properties of Composite Films Based on Chitosan and Methylcellulose. Food Hydrocollids, 21, 66-72. http://www.sciencedirect.com/science/article/pii/S0268005X06000415

[27] Khan, R.A., Salmieri, S., Dussault, D., Calderon, J.U., Kamal, M.R., Safrany, A. and Lacroix, M. (2012) Preparation, Gamma-Irradiation and Thermo-Mechanical Characterization of Chitosan-Loaded Methylcellulose Films. Polymers and the Environment, 20, 43-52. http://link.springer.com/article/10.1007\%2Fs10924-011-0336-y 